\title{
O desenvolvimento da criança com Paralisia Cerebral no ambiente familiar
}

\author{
SofíaRubinstein* \\ MariaHelenadaSivaRamallho*** \\ FranciscoCamargoNetto***
}

\section{Resumo}

Este estudo investiga as contribuições do ambiente familiar para o desenvolvimento da criança com Paralisia Cerebral, nafaixa etáriados 5 aos6anos de idade. Osparticipantes do estudo são trêsfamilias, que têm crianças com diferentes tipos $\mathrm{de} P \mathrm{~Pa}$ ralisia Cerebral.Foram realizadas entrevistas semiestruturadas comasmães das crianças e observações indiretas através de gravações em VT das atividades desenvolvidas pelas crianças, no ambiente familiar.As informações coletadas respondemaos objetivos específicos do estudo que são: descrevero status social familiar; identificar e analisar as atividades realizadas no ambiente familiar, as relações interpessoais da criança com Paralisia Cerebral e os papéis desempenhados durante as atividades, no ambiente familiar.

Palavras-chave: criançascomParalisiaCerebral,desenvolvimento humano, ambientefamiliar.

\section{Abstract}

This study looks at the contributions of the family context to the development of the child with Cerebral Palsy in the 5 to 6 year-old age group. The study participants are three families with children who have different kinds of Cerebral Palsy. Semistructured interviews were carried out with the mothers of the children and indirect observations were made through video tape recordings of the activities carried out by the children in the family context. The data obtained answer to the specific goals of this study, which are: a description of the social status of the family; identification and analysis of the activities carried out in the family context, of the interpersonal relationships of the child with Cerebral Palsy, and of the roles performed during the activities in the family context.

Keywords: children with Cerebral Palsy, human development, family context.

\section{Resumen}

Este estudio investiga las contribuciones del ambiente familiar en el desarrollo del niño con Parálisis Cerebral, en edades comprendidas entre los 5 y 6 años. Losparticipantes del estudio son tresfamilias, conniños con diferentes tipos de Parálisis Cerebral. Se realizaron entrevistas semi-estructuradas con las madres de los niños y observaciones indirectas a través de grabaciones en video de las actividades desarrolladas por los niños en el ambiente familiar.Las informaciones recogidas responden alosobjetivos específicos del estudio que son: describir el status social familiar; identificar y analizar las actividades realizadas en el ambiente familiar, así como relaciones inter-personales del niño con Parálisis Cerebralylos roles desempeñadosdurante las actividades en el ambiente familiar.

Palabras-dave:niñosconParálisisCerebral,desarrollo humano, ambientefamiliar. 


\section{Introdução}

Especificamente, a AssociaçãoBrasileiradeParalisiaCerebral,citadaporGOMESetal.(1995,p. 288), considera a Paralisia Cerebral (PC)como

...o conjunto de alterações oriundas de um determinadoacometimento encefálico, caracterizadoes-

Aolongo da história, aParalisia Cerebralvemsendo entendida, explicada e tratada fundamentalmente pormédicos, fisioterapeutas, terapeutas ocupacionaise outrosprofissionais, enquadrandoascriançascomParalisia Cerebral em uma questãomédico-terapêutica e entendendo-a como uma deficiência.

sencialmente por umaalteraçãopersistente, porémnão estável do tônus, da postura e do movimento que se inicia durante o período de maturação anatomofisiológico do sistemanervoso central.

AParalisiaCerebral podeestaracompanhadadeoutros transtornos como: distúrbios visuais, auditivos, déficitmental, epilepsia, dificuldades respiratórias, de alimentação, transtornos nalinguagem, decomunicação, problemas decondutae outros.

Hádécadas que os profissionais damedicinatentam desvendaras causas dalesãocerebral produzidaduranteodesenvolvimentodoSistemaNervosoCentral, tentandosaberquaissãoas possíveisrepercussões dessalesãono organismo. Assim, quando se pensaem Paralisia Cerebral, o primeiro que vemà mente são conteúdossobreconceitualização, etiologia, diagnóstico, causas, classificações, tratamento, entre outros.

Nãosedesmerecemostrabalhosrealizados naáreada medicina,jáqueconstituemumabase sólidaeimportante para entenderaParalisia Cerebral; noentanto, nãose pretendelimitaroestudoaos diagnósticos, às causase aos tratamentos que sãorealizados comacriança, mascompreenderodesenvolvimentodacriança comPCem seu meio ambiente natural, ecomo esseambienteinfluenciaseudesenvolvimento. Desenvolvimentohumanoentendidocomoprocesso, bioló- gico, cultural eevolutivo, que delineiaaquantidadee a qualidade das experiências adquiridas ao longo da vida.Assim,concorda-secomBRONFENBRENNER (1996,p.5)quandodefineodesenvolvimentocomo “... uma mudança duradoura na maneira pela qual umapessoapercebeelidacomoseuambiente."

Para VYGOSTKI (1997), oambiente nãosóéumacondiçãoparaodesenvolvimentodacriança deficiente, senão tambémafontedessedesenvolvimento. Todavia, ocomponente hereditário, por pequeno que seja,éimportantee participa também nodesenvolvimento. Ésabido,queemfunAcriançacresce em determinado ambiente e as interações comoutraspessoas que participam desse ambiente são essenciais para seudesenvolvimento. Partindo-se destapremissa, ocontexto ambientalé visto como um sistema de inter-relações ou de interdependências entre os vários componentes físicose humanos, que participam dessecontexto.

çãodaprópriadeficiência, as criançascomParalisiaCerebral sofremalteraçõesemseudesenvolvimento,tomando-omaislimitadoeoganhodehabilidadesmaislento. Dependendodagravidadeedainstalaçãoprecocedadeficiência, as oportunidades interativas da criança como meiopodemestarmaisoumenosrestringidas, acentuandoaspossíveisdefasagensdedesenvolvimento.Entretanto,mesmoqueodesenvolvimentodessascriançasocorra deformaatípica, assuasnecessidades básicaspermanecemexistindocomoasdequalquercriança.Assim, ascriançascomPCnecessitamserencorajadasarealizarem diversasatividadesquemaximizemseudesenvolvimento emnível cognitivo, socialemotor, reconhecendosuas potencialidades, assimcomosuas limitações, condições comunsatodosossereshumanos.

Duranteaprocuradematerial bibliográfico, percebeusequeexistemescassaspesquisasemrelaçãoaoambientefamiliarcomoumcontextoquepodeserumpossívelfacilitadordodesenvolvimentodacriançacomParalisiaCerebral.AmaioniadosestudossobrePCenfocam 
odiagnósticoeotratamentodessas crianças. Entretanto,emumestudorealizadoporCURADO,NETO;KOOI (1997), sobreocomportamentolúdicodacriançaportadoradeTrissomia21, constata-seaimportânciada famílianodesenvolvimentodacriança, aodizerque, noenquadramentosocial, "afamíliafuncionacomoo contextoprimárioquemaisinfluencia ocrescimento psicológico,odesenvolvimentoeobem-estardacriança'(CURADO,NETO,KOOIJ,1997,p.85).

Nesse sentido, ocaráterrelevante dopresenteestudo estána abordagem que se faz aoestudar oambiente familiardacriançacomParalisiaCerebral. Considera-se o ambiente familiar como um contexto sociocultural relevanteparaodesenvolvimentodacriançacomParalisiaCerebral.Partindo-sedesse pressupostoopresenteestudopropõe-seaestudaraseguinte questão: comooambientefamiliarcontribui para o desenvolvimentodacriançacomParalisiaCerebral?

Parapoderrespondera essa perguntaelaboram-seo objetivogeral:

- Investigaras contribuiçõesdoambientefamiliar paraodesenvolvimentodacriançacomParalisia Cerebral,nafaixaetáriados 5 aos6 anosdeidade.

\section{Eosobjetivosespecíficos:}

- Descrever ostatussocial familiardacriançacom PC,considerando-seoníveldeescolaridadedospais, jornadade trabalhoe rendamensal.

- Identificare analisar as atividades realizadas,no ambientefamiliar, pela criançacomPC, os brinquedos, objetos eoutros materiais utilizados duranteessas atividades.

- Identificare analisaras relações interpessoais da criançacomPC,comosmembrosmaispróximos donúcleofamiliare comamigos dentrodoambientefamiliar.

- Identificareanalisarospapéisdesempenhadospela criança comPC duranteas atividades realizadas noambientefamiliar.

\section{Pressupostos para análise da criança com Paralisia Cerebral}

Opresenteestudoestáinspiradona TeoriadaEcologia doDesenvolvimentoHumanodeUrieBronfenbrenner (1996), quetem, comoparadigma, odesenvolvimentoenquantoprocessofenomenológiconãoisolado, ou seja, a função do ambiente enquanto sistema determinantenoprocessodedesenvolvimentodoser humano. Nesteestudo, realizou-se umrecortedareferidateoria, aqual subsidia aspectos relevantes dotrabalhoparaatenderaquestãogeradoradoestudo.

Oelementocentral na abordagemecológicaestána visão de que o ser humano e seu ambiente são indissociáveise, portanto,nãopodemserseparadosse oobjetivoforacompreensãode umououtro. Assim sendo,Bronfenbrenner(1992), citadoporRAMALHO (1996,p. 10), define odesenvolvimentocomo "oprocesso através do qual as propriedades dapessoae do ambiente interagem para produzirconstânciaemudançasnascaracterísticas da pessoaatravés da vida." Essadefiniçãofazlembrarque os componentesgenéticos do serhumano estão presentes no processodo desenvolvimento, misturando-se com os fatores ambientais. PELLEGRINI(1991)eBEE(1996) enfatizam a importância de compreender-se as interações entre as várias influências danaturezae do meioambiente.

Oambienteecológicona Teoria daEcologiadoDesenvolvimentoHumanoéconcebidocomoumasérie deestruturas encaixadas, umadentroda outra, como afirmaBRONFENBRENNER(1996), comoumconjuntodebonecas russas. Essasestruturas são chamadasdemicrossistema, mesossistema, exossistemae macrossistema.

NaTeoriadaEcologiadoDesenvolvimentoHumano, também chamadaTeoriados Sistemas Ecológicos, $\mathrm{O}$ microssistema, écompreendidocomoo nível mais imediatopara odesenvolvimentoda criança,seconstitui como o ambiente no qual a criança vivenciae 
cria a realidade de seu dia-a-dia, e onde as pessoas podemfacilmente interagir.As atividades desenvolvidas, as relações interpessoaisestabelecidaseos papéis sociaisdesempenhadoscaracterizam-sepeloselementos doambienteemqueo sujeitoemdesenvolvimento participaativamente, constituindo-secomoos componentesestruturais domicrossistema.

As atividades que a criança realiza sãochamadas de atividadesmolares.Estassãoformas decomportamentosignificativos ou influentes sobreodesenvolvimento. Asformasdecomportamentoconstituídasdeatividades momentânease carentes de significadoeintenção, quenão influenciamodesenvolvimento,sãochamadas deatividades moleculares.

Asrelaçõesinterpessoais, ouestruturasinterpessoaisocorremapartirdomomentoemqueduas pessoasestabelecemumarelação.A presençadesserelacionamentoentre duas pessoas caracterizaaunidade básicadosistema,chamadadedíade.Estaéformadasemprequeduas pessoas prestamatençãoouparticipamnasatividades daoutra,constituindo-secomoumcontextocríticopara odesenvolvimento.Alémdisso, adíadeéocomponente básicodomicrossistema, possibilitandoaformaçãode estruturasinterpessoaismaiores, comotríades, tétrades eassimpordiante. As díades apresentamumprocesso evolutivo, que vãodeestruturas, relaçõessimples, arelaçõesmaiscomplexas.Dependendodotipoderelação estabelecida, dograudecomplexidade, asdíadesseclassificamem:díadeobservacional, díadedeatividadeconjuntae díade primária.

Adíadeobservacionalocomequandoumapessoapresta atenção continuada na atividade realizada por uma outrapessoaeelapercebequeestásendoobservada, emitindoalgumtipoderespostaàatençãoqueestásendodemostrada.Essetipodedíade,facilmenteevoluipara umadíademaisativaecomplexacomoadíadedeatividadeconjunta.Estadíadeseproduzquandoduaspessoas sepercebemasi próprias, fazendoalguma coisa juntas,mesmoqueelasnãoestejamfazendoamesma coisa.Porsuavez, as díades primáriassãootipoderelacionamentointerpessoalmaisduradouro, poiselascon- tinuamaexistirfenomenologicamenteparaambosos participantes, mesmoquandoeles nãoestãojuntos. Mesmoestandoseparados,fazendoatividadesdiferentes eemdiferentesambientes, cadaumdosmembrosaparecenos pensamentosdooutro, sendoobjetos defortes sentimentos emocionaise continuamainfluenciaro comportamentoreciprocamente.

Ospapéissociaisdesenvolvidos pelascrianças, sãoentendidoscomoumasériedeatividadeserelaçõesesperadas de uma pessoa que ocupa uma determinada posiçãona sociedade de outros em relaçãoàquela pessoa(BRONFENBRENNER1996).Essespapéisidentificam-secomos rótulos usados paradesignar as distintas posições sociais em uma cultura, os quais são diferenciados pelaidade, sexo, ocupação ou o status social queapessoa ocupana sociedade.

Atéaqui,referiu-seaos papéis sociais vivenciados pelascriançasemdesenvolvimento.Entretanto, OLIVEIRA(1988)chamaaatençãopara outra dimensãono jogodos papéis. Porumlado, observam-se os papéis desempenhadosnasatividades deencenaçãodarealidade, os quais foram abordados por Bronfenbrenner (1996); por outro, opapel interpessoal, manifestado nas interações entre as crianças, fundamentado por Mead,MorenoePiaget.OLIVEIRA(1988)ressaltaque ascrianças, desde muitocedo, assumemestruturas de interaçãomesmoquandobrincam sozinhas, expressandoessescomportamentos.Mesmosemaindaindicar a existência de interação explícita, a própria criança passaadesempenhar partes de umahistória vividaanteriormente. A autoramostraqueas crianças envolvem-seeminteraçõestantonas brincadeiras de faz-de-conta, ondeojogodepapéis visualiza-semais claramente, em explorações conjuntas deobjetosesituaçõesquantoem disputas ou cooperação.

Comospressupostosteóricosanteriormentedescritos, tem-se comofoco central, o estudo da criança com ParalisiaCerebral noambientefamiliar, sendoconstituído pelo microssistema: as atividades, as estruturas interpessoaise os papéis sociaise interpessoaisdesempenhados poressacriança. 


\section{O ambiente familiar como contributo para a criança com Paralisia Cerebral}

OambientefamiliarconformeCAMPION(1987),significaumconjuntodeparteseminteraçãocontínua queconstituem, unidas, um conjuntosuperioràsoma dessaspartes.Existeatendênciadecadaumadessas partes a afetara todas às demaise ao mesmo tempo serafetadaporelas.

Neste estudo, aborda-se especificamente oambientefamiliar que, crê-se, éo primeiro ambiente que acolhe a criança em desenvolvimento. Dessa maneira, concorda-secomSERRANO;NETO(1997), quandodestacamque acriançanascenoseiode uma famíliae, progressivamente, iráconquistando múltiploscontextos, comoaescolaeacomunidade social. Entretanto,eventos extemos aocontextofamiliarpertencentesaoutros ambientes podeminfluenciardiretaouindiretamentea criançaem desenvolvimentoe vice-versa.

Revisandoestudossobreavidafamiliar,Hoffman(1984), citadoporRAMALHO(1996),destacaquatrovanáveisque, noentendimentodele, podemafetarafamiliaeacriança: ascondiçõeseconômicasgerais,aclassesocioeconômica, otrabalhodopaieotrabalhodamãe.Hoffmanenfatiza queodesenvolvimentodacriançamuitas vezeséinfluenciadopelostatuseconômicodesignadopelaocupaçãodo pai.Osconstituintes da vidadacriança, comoasaúde, nutrição, educaçãoe, ainda, oseu ambientefísico, vizinhoseamigos, alémdospadrõesdeeducaçãodacriança eonúmerodeseusfamiliares, suaestruturaautoritáriae suaestabilidade,sãorelativosàclasse social.Noquese refereàclassesocial,COCHRAN(1993)descrevequea rendafamiliar,onível educacional dos pais, ostatusea complexidadedaprofissãodosmesmos,sãofatoresque contribuemparadeterminaremqual classesocial afamiliaestálocalizada.Bronfenbrenner(1986), citadopor RAMALHO(1996),apresentatêssistemasqueprovavelmentepodemafetarodesenvolvimentodacriança:olugardetrabalhodos pais,redessociais, einfluênciadacomunidadenofuncionamentofamiliar:SERRANO;NETO (1997)aindaressaltamquepesquisasfeitascomcrianças emidadepré-escolartêmdemostradoqueodesenvolvimentodelas pode estarrelacionadoaonível socioeconômicodafamília, comascondiçõesdehabitaçãoeos processos relacionados comos padrões de interação parentais,comoselementosdefratriaecomosguposde socializaçãoemjogosedinâmicasdeaventura.

EstudostealizadosporMARTINEZ(1992),RAMALHO (1996),SERRANO;NETO(1997),NETO(1997),CURADO;NETO;KOOIJ(1997)eCARVALHO(1998)mostramaimportância do ambientefamiliare dos diversoselementosdocontexto social nodesenvolvimento (cognitivo, socialemotor) de crianças pré-escolares, escolarese portadoras denecessidadesespeciais.

\section{Metodologia}

Oparadigmaescolhidoparaesteestudofoiomodelo pessoa-contexto,devendoserexploradoquantoàextensãonaqualomesmo ambientepodeterdiferentesefeitossobresereshumanoscomdiferentescaracterísticas pessoais. Oenfoquefoioqualitativo,noqual seconsideratodaainformaçãodisponibilizadapelosinformantes comoimportante, estudandoofenômenoemseucontexto.Caracteriza-seesteestudo,também, comodescritivo-interpretativo, porinvestigar, atravésdadescrição, interpretaçãoe dacompreensãooscomponentesestuturaisrelevantesaodesenvolvimentodacriançacomPC, tendocomofocooambientefamiliar.

\section{Participantes da pesquisa}

Fizeram partedo presenteestudotrêsfamílias decriançascomdiagnósticodeParalisiaCerebral.DuascriançasforamescolhidasnoCEREPAL-CentrodeReabilitaçãodePortoAlegre;eumanoEDUCANDÁRIO SÃOJOÃOBATISTA-CentrodeReabilitaçãofísicae EducaçãoEspecial.Emlinhasgerais, essasfamíliasse distinguempor apresentarumbaixonível de instrução, uma renda mensal baixae residirem casas humildes, localizadasembairros periféricose pobresda cidadedePortoAlegre. 
OQuadro 1 caracterizaas crianças que participaram doestudo.Sãoconsideradosos aspectosidentificação dacriança, sexoeidadenomomentodoestudo, ediagnósticodaParalisiaCerebral.Optou-seporidentificar as crianças com uma letra, respeitando-se a sua identidade.

Quadro 1. Caracterização das crianças

\begin{tabular}{|c|c|c|c|}
\hline $\begin{array}{l}\text { Identificação } \\
\text { des crianças }\end{array}$ & Sexo & Idade & $\begin{array}{l}\text { Diagnódico } \\
\text { médico }\end{array}$ \\
\hline G & Mesoulino & $\begin{array}{c}5 \text { anose } 11 \\
\text { meses }\end{array}$ & $\begin{array}{c}\text { PCoom } \\
\text { hemipareiaà } \\
\text { dreita }\end{array}$ \\
\hline D & Feminino & $\begin{array}{c}6 \text { anose } 10 \\
\text { meses }\end{array}$ & $\begin{array}{l}\text { PCespéstica com } \\
\text { terraperesa }\end{array}$ \\
\hline M & Mesculino & $\begin{array}{c}6 \text { anose } 5 \\
\text { meses }\end{array}$ & $\begin{array}{c}\text { PCespéstica com } \\
\text { hemiparesia à } \\
\text { esquerda }\end{array}$ \\
\hline
\end{tabular}

Os diagnósticos médicos foramobtidos através dos prontuários das criançasnosCentros de Reabilitação. Percebe-se que ograu de comprometimentomotor variadesdeaparalisiadeumhemicorpo,emduas crianças, até as alterações nos membros superiores einferiores, emumacriança.

\section{Instrumentos para coleta das informações}

Considera-seque os instrumentosquemais seajustam ao presente estudo são a entrevista semiestruturadaea observação indireta, atravésde gravaçõesemVT.Osinstrumentosescolhidosforam testadosatravésde umestudo preliminarenãohouvenecessidadederealizarmodificações.

Para este estudo, optou-se pela entrevista semiestruturada, que permite obterinformações de questões concretas, previamentedefinidas pelopesquisador,e,aomesmotempo, ofereceliberdade aoentrevistadoparaabordaraspectosrelevantessobreoquepensa(NEGRINI,1999). Asentrevistasforamrealizadas pela própria pesquisadora, comcadamãe das crian- ças, individualmente, egravadas emfitas cassete. As perguntas procuraramrespostas aosseguintestópicos: ocupação dos pais; horáriode trabalhodeambosos pais; nível de escolaridade do pai e da mãe e renda familiarmensal. Outras perguntastambémforamrealizadas duranteasentrevistas, entretantonemasperguntasnemasinformaçõesobtidassãopertinentesde serem discutidasnesseartigo.

AobservaçãoéentendidaRODRÍGUEZGÓMEZ;GL FLORES;GARCÍAJIMÉNEZ(1996)comoumprocedimentodecoletadeinformaçõesqueproporcionauma representaçãodosfenômenosqueestãoemestudo.Esse procedimento temum caráter sistemáticoe tem que estar orientado poruma pergunta, propósito ou problema. O papel do observador foi não-participante, individual, eas observações foram realizadas emsituações concretas, nacasa das crianças com PC, após autorizaçãoporescritodos pais. Ocomportamentoda criançadurantearotinadiáriafoi gravadoem VT, utilizando-seumacâmeramóvel. Aduraçãodas gravações acompanharam as atividades, relaçõesinterpessoaiseos papéisdesempenhados pelacriançanoambientefamiliar, sendoque esse tempovariou de 23 a 87 minutos. Realizaram-se4observaçõesem VTdurante asemana paracada criança.

As atividades, as relaçõesinterpessoaiseos papéisforam registrados, levando-se em contaa duraçãodas atividades, a ocomência, os objetos, asituaçãode execução(sóe/ou acompanhado) easinterações entrea criança a a pessoaenvolvida. Ocomportamentoda criançafoi registrado a cada minuto, procurando-se descreverdeformaobjetivaecompletacadaatividade realizada pela criança, incluindo-se outras pessoas envolvidas, osespaçosemqueas atividadesforam executadas, es materiais utilizados ou que serviram de suportepara suarealização. Nototal,foram descritas 563 atividades molares. Asrelaçõesinterpessoaisforam detectadas dentrodas atividades molares, pelas diferentesformas deinteração da criançacomoutras pessoas. Os papéisforam visualizadosnos comportamentos das crianças durante as atividades molares. 


\section{Procedimento de análise interpretativa das informações}

InspiradonaTeoriadaEcologiadoDesenvolvimento Humano, apresentada por BRONFENBRENNER (1996), mostra-se aanálise interpretativados resultados, a partir das informações adquiridas através das entrevistas semi-estruturadas edas observaçõesutilizando-sedegravaçõesem VT.

\section{Entrevista semi-estruturada}

Asentrevistas realizadasforam transcritas pelaprópria pesquisadora, sem realizar alterações dos vocábulos utilizadosnos depoimentose/ounas respostaseentreguesàsmães paraqueelas pudessem, após verificaro conteúdodasmesmas, validara veracidadedasinformações.

Ostatus social familiar, foi analisado da seguintemaneira:paraonível deescolaridadedos paisforam consideradas três categorias. A primeira categoriacompreendeoensinofundamental incompleto; asegunda, oensinofundamental completoeoensinomédio incompleto; eaterceiracategoria, oensinomédiocompleto. Aprimeirae segundacategoriasforamconsideradas baixonível educativoe aterceira, nível médio.

A jornada de trabalho foi analisada tanto para o pai comopara a mãe, considerando-se duas categorias. Um turno, quandoé manhã, tardeounoite integral quandoédoisturnos.

A análise darendamensal percapita fundamentouseemumadistribuição, baseando-seem valores relativos ao salário mínimo vigente, classificando-se as familiasemduascategorias:menosfavorecidas $(\leq 2,5)$ emaisfavorecidas $(>2,5)$.

Para a descriçãoe análise interpretativados conteúdos das entrevistas foi elaborada uma categoria de análise, denominada contextosociocultural, ondeestãocontidas as informações referentes ao status social familiar:níveldeescolaridadedospais, jomadade trabalhoerendamensal "percapita", além de informações referentesàocupaçãodos pais.

\section{Observação em VT}

Aelaboraçãointerpretativadas atividades espontâneas, realizadas no ambiente familiar, partem das narrativas pormenorizadas dos comportamentos da criança. Essas descrições adquirem sentido através das relaçõesentreos diferentestiposdecategorias deatividades molares, definidas durante as observações, a complexidade, as estruturas interpessoaise os papéis experenciados no contexto de desenvolvimento (RAMALHO,1996).

As atividades visualizadas duranteas observaçõesforamanalisadasa partirdediversos tiposde categorias, definidas, a partirdoestudo preliminar. Osconceitos dos sistemas decategorias foraminspiradosemestudos anteriores de PEREIRA; NETO (1994), BRONFENBRENNER(1996),RAMALHO(1996),CURADOetal.(1997)ePereira(1993), citadoporNETO (1999). Ressalta-se que algumas categorias de atividades propostas pelos autores foram modificadase adequadasàsnecessidadesdesteestudo, ficandoassim constituídas: a) atividades audiovisuais; b) jogos didáticos; c) atividades artísticas; d) atividades de fazde-conta; e) atividades debiblioteca; f) atividades de coordenaçãodosmovimentos; g) atividadescombola; h) atividades de equilíbrioei) atividades de manipulação.

Acomplexidadeestrutural dasatividadesdizrespeitoàs categorias descritivas:quantidadedeatividadesmolares realizadas durante a observaçãono contextodacasa; perspectivatemporal ampliada, noque serefereàparticipaçãodacriançanodecomerdasobservações, ematividades progressivas, dentrodemetasestruturadasexplícitas, emumcursoúnicodeação, porémconstruídas emsubmetas sequienciais.Decomemdacomplexidade os eixoscomplementares, que refletemoselementos: relaçõesinterpessoais, referentesaocampoecológico, percebidos, na participação da criança comParalisia Cerebralemsistemasinter-pessoais (díades deobservaçãoe de atividade conjunta, tríades); papéis, comrelaçãoàmodificaçãoou expansãodoespaçovivenciado, pormeiodafantasiaoureconstruçãoreal doambiente 
objetivo.Ospapéissociaiseinterpessoaisforamaqueles categorizados apartirdainterpretaçãodasobservações das atividades molaresrealizadasnocontextodacasa pelascriançascomParalisiacerebral(RAMALHO,1996). Essesnãotem expressãonumérica, entretantorealizaseumadescriçãodosquetiverammaiorocorrência. As tendênciasnasrelaçõesinterpessoaisforamanalisadas apartirdasdíadesdeobservaçãoeatividadeconjunta, observadasduranteoscomportamentosrealizadospelascriançascomdiferentesobjetoseenvolvimentosno ambientefamiliar.

A articulaçãodos resultados dasentrevistase das observaçõesobtidos einterpretados apósreflexãoe discussão, talveznos permitamdemonstrarqueoambiente familiar sejaum determinante favorável parao desenvolvimentodacriançacomParalisiaCerebral.

\section{Apresentação e discussão dos resultados}

Explicita-seaseguirasinformações referentesaocontextosociocultural coletadascomasentrevistas semiestruturadas.

OQuadro2proporcionainformaçõessobreonívelde escolaridade, ocupação dos pais, jornadade trabalho erendamensal "percapita" dastrêsfamillias queparticiparamdapesquisa.

Quantoao status social das trêsfamílias de crianças comParalisiaCerebral, verificou-sebaixoníveldees- colaridade, pois somenteumamãecompletouoensinomédio.Emrelação ao trabalho, constatou-sejornadaintegral paraos pais, diferente das mãesemque estão odiatodonolar.Arenda mensal "percapita" inferiora 2,5 salários mínimos; narealidade, orendimentomensal "percapita" maioréde 1 saláriomínimoeomenor de 0,27 saláriosmínimos.

Apresenta-se, seguidamente, as atividadesmolaresrealizadas pelas crianças, organizadas previamenteem categorias de atividades, os brinquedose outros objetos usados durante as mesmas, assim como as relações interpessoais e os papéis sociais e interpessoais experienciados durantea execuçãodas diversas atividadesnoambientefamiliar.

AsdiferentesatividadesrealizadaspelascriançasnocontextodedesenvolvimentosãomostradasnaFigura 1 .

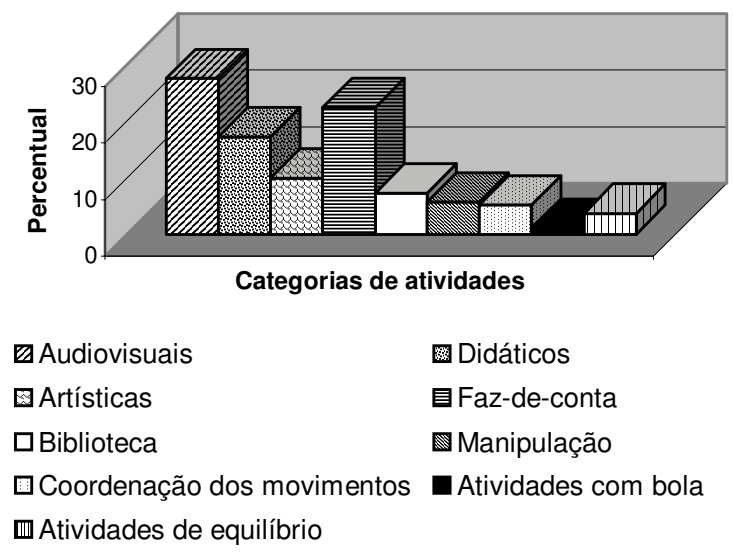

Figura 1. Categorias de atividades realizadas no ambiente familiar

Quadro 2. Status social e ocupação dos pais

\begin{tabular}{|c|c|c|c|c|}
\hline $\begin{array}{l}\text { Idantificação } \\
\text { paisfillho(a) }\end{array}$ & Nvel de Esodaricade & Oappação & Jumada de trabalho & $\begin{array}{c}\text { Penda mensal "per } \\
\text { capita" }\end{array}$ \\
\hline $\begin{array}{l}\text { Née- G } \\
\text { Pai }\end{array}$ & $\begin{array}{l}\text { Ensino médo completo } \\
\text { Ensino fund }{ }^{*} \text { completo }\end{array}$ & $\begin{array}{l}\text { Comeraíria } \\
\text { Mecânico }\end{array}$ & Menhã etarde & 1 slário mínimo \\
\hline $\begin{array}{l}\text { Nee- D } \\
\text { Pai }\end{array}$ & $\begin{array}{l}\text { Sétima sóvie ensino fund } \\
\text { Quarta sórielensino fund }\end{array}$ & $\begin{array}{l}\text { Dolar } \\
\text { Pedréro }\end{array}$ & Menhã e tarde & $\begin{array}{l}\text { 0,27 slários } \\
\text { mínimos }\end{array}$ \\
\hline $\begin{array}{l}\text { Née- M } \\
\text { Pai }\end{array}$ & $\begin{array}{l}\text { Pimero and ensino médo } \\
\text { Segundb and ensino médo }\end{array}$ & $\begin{array}{l}\text { Dolar } \\
\text { Vendedor }\end{array}$ & Menhã e tarde & $\begin{array}{l}\text { 0,42 slários } \\
\text { mínimos }\end{array}$ \\
\hline
\end{tabular}

*Ensino fund. = Ensino fundamental 
Quantoàscategoriasdeatividadesqueascriançasexecutam no ambiente familiar, destacam-se as atividadesaudiovisuaiscom $28 \%$, seguidasdas atividadesde faz-de-conta, 22\%,eosjogos didáticos,com $17 \%$.Com menorpercentualé possível visualizar as atividades artísticas, $10 \%$, eainda compercentual inferioràanterior categoria constatam-se as atividades de biblioteca, com $7 \%$.Asatividadesquerequeremumamaior movimentaçãoporpartedequemasrealiza, como: as atividades de manipulaçãocom $6 \%$, de coordenação dosmovimentos, $5 \%$, as atividades deequilibriocom $4 \%$ e as atividades com bola, $1 \%$, apresentam percentual muito pequenoquandocomparadasàs atividadescompercentuaismaiores.

Esse resultadomostrandoaelevada presençadas atividades audiovisuaisnarotinada criança comParalisiaCerebral, assemelha-se aos resultadosobtidosem estudosrealizadosporMARIINEZ(1992)eCARVALHO (1998), queapontamqueaatividadede assistirtelevisãoestámuitopresentena vida das criançascom problemas dedesenvolvimentoeParalisiaCerebral.

Sobreasatividadesdefaz-de-conta, CARVALHO(1998) referequeessas atividadesestãopresentesnarotinade vidadequatrocrianças, comidadesentre os $4 \mathrm{e} 6$ anos, que participaram de sua pesquisa e acrescenta que, quando a criançacriauma atividade como ade brincardecasinha ou deprofessora, ela vive uma situação imagináriaemque pode-se observar, efetivamente, $\mathrm{o}$ iníciodarepresentaçãodepapéis.

Referindo-seàs práticas deescrever, desenharepintar, CARVALHO(1998)afimmaqueàmedidaqueascrianças com Paralisia Cerebral entramem contato com essetipodeatividades aparecem dificuldadesemsua realização, demaneiramaisfortedoqueoprazerque delaspoder-se-iaobter.

Ressalta-sequeas atividadesdecoordenaçãodosmovimentos, de equilíbrio, as atividades combolae as atividadesdemanipulaçãonãoforam visualizadasna rotina da criança de sexo feminino, oque podeestar relacionadoàs maiores dificuldades motoras quea criança apresenta. Entretanto, destaca-se que essas quatrocategoriasdeatividadestambémsãopoucopraticadas pelas outras duas crianças.

Atéaqui, basicamente, as atividadesforamanalisadas, emtermos dequantidadedecadacategoriadeatividades visualizadasnoambientedacasa. Paracompletara análise, a seguir as atividades serão analisadas sobo pontode vistadaperspectivatemporal ampliada.

Naanálisedas atividades visualizadas duranteas observações, depreende-sequeas atividadescombolaapresentamsubmetas sequienciais, dentrodeumúnicocursodeação:acriançaseenvolveemumasequiênciade passos atécompletar aatividade. Nojogode futebol,a criançacomeatrásdabola, chutaabolacomopé,come enquantoempurraabolacomopé,joga abolacoma mão,entreoutros movimentos, atéatingirametaqueé fazerogol. Nojogodebasquete, asituaçãoésimilar:a criançacaminhaquicandoabola, quicaabola, estandodepé, em determinadolugar, corre comabolana mão,entreoutros movimentos, atétentarfazeracesta. Emboraessesdoisjogoscategorizados dentrodas atividades com bola sejam construídos em submetas sequienciais,nãosevisualizamcomoatividadesprogressivasnodecorrer das sucessivasobservações, masse mostramprogressivasem determinados dias de observação. Asrestantes categorias de atividadesnão apresentam complexidade estrutural do pontode vistada perspectivatemporal ampliada.Emsíntese, as categorias deatividadesquemostram complexidadeestrutural dopontode vista daquantidade, eque se apresentam duranteassucessivas observações, carecem decomplexidadequantoà perspectivatemporal ampliada, enquantoqueasatividadescombola, quepossuemcomplexidadeestruturalemrelaçãoàperspectivatemporal, aparecemvagamentenarotinadascrianças.

Nadescrição das categorias de atividades molares, depreendem-seosbrinquedoseoutros objetosutilizadosduranteas atividades, porémapresenta-sesomente aquelesquese visualizaramcommaisfrequiência. $\mathrm{Nas}$ atividadesdefaz-de-contaosbrinquedos visualizados são: carros, caminhões, bonecas, bonecos, telefone, vassouraefuteboldepregos; otelevisoréoobjetoutilizado 
nasatividadesaudiovisuais; osblocos, quebra-cabeças, obaralho, CDse suascaixas, nosjogos didáticos. Nas atividades artísticas encontra-seas folhas de papel,os lápis de cor e a guitarra; livros comfiguras, desenhos pintados pelas crianças, folhas de papele canetas, nas atividadesdebiblioteca. Duranteasatividadesdemanipulaçãosãousadasmoedas, enas atividadesdecoordenaçãodosmovimentos, as crianças brincamcomojogo debolicheeobalãoinflável.Porúltimo, nasatividades deequilibrio,oobjetoéabicicleta, enas atividadescom bola, acestade basquetee abola.

Emrelaçãoàsestruturasinterpessoaisqueacompanharamasatividadesexecutadasnoambientefamiliar,apresenta-seaFigura2,emqueseexplicitaopercentualde díades deobservaçãoe atividade conjuntanototal de relações interpessoais. Nãoforamobservadastríades durantearealizaçãodasatividades molares.

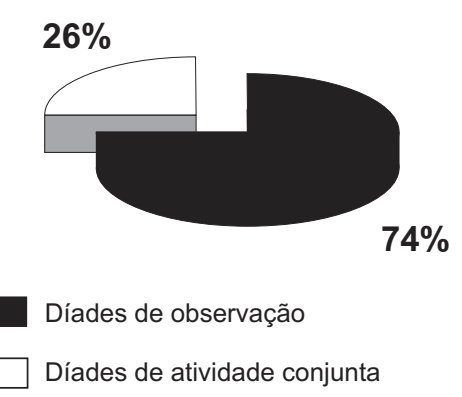

Figura 2. Relações interpessoais - díades de observação e atividade conjunta

AFigura2mostraqueexisteumpredomíniodas díades deobservação sobreas deatividadeconjunta, durante as atividades molares praticadas pelas crianças. Nas díadesdeobservação, nãosignificaqueacriançaesteja realizando uma determinada atividade sozinha. Atravésdasobservaçõesconstatou-sequeacriançapode estarsozinhaduranteaatividade, porém geralmente amãeestásempre porperto, interagindocomacriançaeestacomamãe.

A tabelaaseguirexplicitaaquantidadeeopercentual dedíades deobservaçãoe atividadeconjunta, emcada categoria de atividades realizadas pelas criançasem desenvolvimento, noambientedacasa.
Tabela 1. Quantidade e percentual de díades de observação e atividade conjunta em cada categoria de atividades

\begin{tabular}{|c|c|c|c|c|c|}
\hline \multirow[t]{2}{*}{$\begin{array}{c}\text { Categorias de } \\
\text { atividacks }\end{array}$} & \multicolumn{2}{|c|}{$\begin{array}{l}\text { Dadbsce } \\
\text { Cbsenvação }\end{array}$} & \multicolumn{2}{|c|}{$\begin{array}{l}\text { Diacesde } \\
\text { atividade } \\
\text { cojiunta }\end{array}$} & \multirow[t]{2}{*}{$\begin{array}{l}\text { Todal de } \\
\text { atividades }\end{array}$} \\
\hline & Quant. & $\%$ & Qant. & $\%$ & \\
\hline Audoisuais & 155 & 100 & 0 & 0 & 155 \\
\hline Didáticos & 23 & 24 & 74 & 76 & 97 \\
\hline Atísticas & 46 & 82 & 10 & 18 & 56 \\
\hline Faz-deconta & 114 & 90 & 12 & 10 & 126 \\
\hline Bblideca & 29 & 71 & 12 & 29 & 41 \\
\hline Menipulação & 18 & 56 & 14 & 44 & 32 \\
\hline $\begin{array}{c}\text { Cordenação } \\
\text { dos movimentos }\end{array}$ & 4 & 14 & 25 & 86 & 29 \\
\hline $\begin{array}{c}\text { Aividades com } \\
\text { bda }\end{array}$ & 6 & 100 & 0 & 0 & 6 \\
\hline $\begin{array}{l}\text { Aividades de } \\
\text { equilíbrio }\end{array}$ & 21 & 100 & 0 & 0 & 21 \\
\hline Tdal & 416 & 74 & 147 & 26 & 563 \\
\hline
\end{tabular}

DaleituradaTabela 1, depreende-sequeas díades de observaçãosãootipoderelaçãointerpessoal quemais ocorredurante as diferentes atividades molares.

Analisando-se as díades em cadacategoria de atividades, destaca-se que, durante as atividades audiovisuais, nas atividades combolae nas atividades de equilíbrio somente se manifestaa díade de observação.Esse tipodedíadetambémseapresentacomalto percentual durante as atividades de faz-de-conta, $90 \%$, as atividades artísticas, $82 \%$, eas atividades de biblioteca, em que as díades de observação obtêm $71 \%$. Nas atividades demanipulação, a díade de observação obtêm $56 \%$ sobre o total de relações interpessoais, noentanto, a diferença de percentual coma díade de atividade conjunta nãoé tãonotória quantonas categorias anteriores. Todavia, nos jogos didáticose atividades decoordenaçãodosmovimentos predomina a díade de atividade conjunta, apresentando-se com percentuais de $76 \%$ e $86 \%$, respetivamente.Confere-sedessamaneira, quesóem duascategorias deatividadesadíadedeatividadeconjunta predomina sobre a díade de observação. 
Percebe-se queas atividades audiovisuais eas atividades defaz-de-contaapresentamalto percentual de execuçãono cotidiano das crianças. Entretanto, carecem de díades de atividade conjunta no primeiro caso,e, no segundo, apresentam-se poucas díades de atividadeconjuntadurante essas atividades. Porém, durante os jogos didáticos, que tambémseapresentam freqüientemente na rotina das crianças, ainda que com menorincidência que as atividades audiovisuais, visualiza-se alto percentual de díades de atividadeconjunta.

Quantoaos componentes dafamíliaqueparticipam ativamentedas atividades juntocomascriançasconstata-seemprimeirolugar,acompanhiadamãe.Amãe está presenteem todas atividades em que ocorrem díades de atividade conjunta, no entanto, durante os jogos didáticos, nas atividades de coordenação dos movimentose nas atividades de manipulação, a presençadamãeéobservada commaior assiduidade. A companhia materna em muitas das atividades realizadas pelas criançasnocontextofamiliartambémfoi evidenciadaporRAMALHO(1996),emumestudorealizadocom crianças pré-escolares. A companhiada avóeum primoéconstatadadurante os jogos didáticos,eduranteas atividades defaz-de-contaverifica-se apresençadeumirmão. Não se evidencia a companhiadopainem de amigos nas atividades realizadas pelas crianças no ambientefamiliar.Anãoparticipaçãodopainas atividades molares praticadas pelascrianças, justifica-se pelajornadade trabalhodeles durante os dias de semana, e foi nos dias úteis que as criançasforamobservadasatravésdegravaçõesem VT.

Ospapéissociaiseinterpessoaisdesempenhadospelas criançasem desenvolvimentoestãodiretamenterelacionados não só às atividades, mas, também, ao envolvimento de outras pessoas e aos brinquedose objetosutilizadosduranteas mesmas.

Durante as atividades audiovisuais, oúnico papel visualizadoéodeespectador, constituindo-se umpapelpassivo.NaopiniãodeCARVALHO(1998), aatitudedascrianças frenteà televisãoéde total passividade, econsideraqueessecomportamentoésemprees- perado frente a esse veículo de comunicação. Nas atividades de faz-de-conta, vários papéis sociais são visualizados: defisioterapeuta, de condutor de veículos, detelefonista, de mãe, decavaleiroe de jogadorde futebol. Aqui, ascrianças agem comosefossempersonagens de determinadas situações da vidacotidiana, utilizandodiferentes brinquedose/ouobjetos paraexecutar comeles um gestorepresentativo. Opapelde condutorde diversos veículos foiomaisencenadopelas crianças, os outros apareceram vagamente. Ospapéisdeconstrutore de jogador decartas constatam-se nos jogos didáticos. Durante as atividades artísticas, visualizam-se os papéis de desenhista/pintor e instrumentista; enquantoque nas atividades debiblioteca, observa-se os deobservadore escritor.Nasatividades de manipulação, as crianças desenvolvemos papéis sociais de jogador, arrumadeira, construtore observador,eduranteas atividades decoordenaçãodos movimentos, os papéis de jogadordeboliche, lutador, jogador de futebol e o papel interpessoal de manipulador.Esteúltimopapeléobservadoquandoa criança explora oobjetocomoqual elaestábrincando, assumindo uma estrutura de interação de manipuladorcomesse objeto, semexistirainteração diretacomoutra pessoa. Portanto, nestecasoéconsideradocomoexistindoumpapel interpessoal quando a criança brinca com algumbrinquedo, porém sozinha. Emrelação às atividades de equilíbrio, encontram-se opapel de ciclistae, por último, nas atividadescombola, observa-sesomenteopapeldejogador defutebolebasquete.

Verifica-se que os papéis sociais sãoos que predominamnas atividades realizadas pelas criançascomPC que participaram do estudo. Contudo, um papel interpessoal foi visualizado em duas ocasiões: ode manipulador.Essa ausênciadepapéis interpessoais esclareceuumarealidadeque já foi mostrada anteriormente, relativaàs relaçõesinterpessoais, eespecificamenteàescassaparticipaçãodas criançasemdíades deatividade conjuntadurante as atividades. Nocaso dos papéis sociais, estes podem servivenciados pelas crianças semoenvolvimentodiretodeoutras pessoas duranteas atividades, noentanto, seriamaisfavorável 
se as diferentes formas de atuação das crianças, em diversas situações, estivessem acompanhadas da interaçãocomoutras crianças ouadultos, e, de preferência,interaçõescomplexas, oquenãofoi visualizado naanálise dasobservações.

\section{Considerações finais}

AcriançacomParalisiaCerebral, comoqualqueroutracriança, para se desenvolvernecessitados processos dematuraçãodo seu organismo, eprecisaestabelecerinterações comoseu meio para adquirirascondições necessárias visandotomar-se um ser humano compossibilidadesdeseintegrarà sociedade. Os processos dematuraçãodoorganismonãoforamalvodo presenteestudo, porém, as interaçõescomoseumeio foramabordadas, através doestudo do ambientefamiliar, onde a criança com Paralisia Cerebral está inserida.

Os resultados apresentados anteriormente permitem responderàquestãogeradoradoestudo: como oambiente familiarcontribui nodesenvolvimento dacriançacomParalisiaCerebral?

Oambientefamiliar disponibilizaetenta criar (dentro das suaspossibilidades) condições paraque a criança vivencie atividades agradáveisdentrodoespaçode domínio dos pais (casae suasdependências).Contudo, acredita-sequeo status social das famíliasestudadas,no presenteestudo, influência muito a disponibilidadeque oambientefamiliar
Pode existiraintenção, por parte dospais, de oferecer umambiente rico em possibilidades de experimentação emovimentação, mas, de fato, na rotina de vida dascrianças comParalisia Cerebral, evidenciou-se uma complexidade estrutural das atividades, tendendo a realizações com poucas díades de atividade conjunta, e um ambiente pouco variado em diversidade de atividades e nenhum envolvimento com pessoas alheias àfamilia. tememoferecerexperiências significativas paraacriança. Principalmente, a baixa renda mensal "per capita",eobaixonível deescolaridade dos pais transformamoambientefamiliaremumuniverso pobre deestímulo.

OdesenvolvimentodacriançacomPCéumprocesso que, certamente, deve seralimentadoerealimentado diariamente, noambiente familiar, nãoapenasemrarosmomentosouduranteatividadesespecíficas como foi constatado. Dessa maneira, daforma comooambientefamiliarestáestruturado, contribui pobrementenodesenvolvimentodacriançacomParalisiaCerebral.

Considerando-sequeoambientefamiliaréoprimeirocontextoquepossibilitaa vivênciadeatividadesea interaçãocomoutras pessoas, énecessárioinvestirnesseambiente, para que possa oferecer diversidade de oportunidades às crianças comParalisia Cerebral, e àspessoasque formamjuntocomelasonúcleofamiliar.

\section{Referências}

BEE, Helen.A criançaem desenvolvimento. 7.ed.Porto Alegre:ArtesMédicas, 1996.

BRONFENBRENNER,Urie.Aecologiadodesenvolvimento humano: experimentosnaturaise planejados.PortoAlegre:Artes Médicas, 1996.

CAMPION, Jean. Elniño en su contexto: lateoría de los sistemas familiares en la psicología de la educación. Barcelona: Paidós, 1987.

CARVALHO,LígiaMariadeGodoy.Atividadeslúdicase acriança com paralisia cerebral: ojogo, obrinquedoe abrincadeiranocotidianodacriançae dafamília. 1998. 170f.Dissertação(MestradoemEducaçãoFísica). UniversidadeEstadual de Campinas, Campinas.

COCHRAN,Moncrieff.Parenting andpersonal social networks. In:LUSTER, Tom;OKAGAKI,Lynn(Ed.). Parenting: an ecological perspective. Hillsdale:LawrenceErlbaum, 1993.chp. 6,p. 149-178. 
CURADO,MariaAlice;NETO,Carlos;KOOIJ,RimmertVander: Comportamentolúdicoda criançaportadora de trissomia21. In: NETO, Carlos(Ed.).Jogo \& Desenvolvimento da criança. Lisboa:EdiçõesFMH, 1997.p.83-98.

GOMES,Claudioetal..ParalisiaCerebral.In:LIANZA,Sergio (Coord.). Medicina de reabilitação. 2.ed. Rio de Janeiro: GuanabaraKoogan, 1995.cap.20,p.288-303.

MARTINEZ,ClaudiaMariaSimões.Atividadesebrincadeiras na vida da criança com problemas no desenvolvimento no início dos anos 90: a visão dos pais. 1992. 150f.Dissertação (MestradoemEducaçãoEspecial).UniversidadeFederaldeSão Carlos,SãoCarlos.

NEGRINI, Airton. Instrumentos de coletadeinformaçõesna pesquisaqualitativa. In:MOLINANETO, Vicente; TRIVIÑOS, Augusto N. S. (Org.). A pesquisa qualitativa na educação fisica: alternativasmetodológicas. Porto Alegre:Editorada UniversidadeFederal doRio Grande doSul: Sulina, 1999.p. 61-93.

NETO,Carlos. Tempo\& espaçodejogoparaacriança: rotinase mudanças sociais. In:NETO,Carlos.(Ed.).Jogo \& Desenvolvimento.Lisboa:EdiçõesFMH, 1997.p. 10-22.

NETO,Carlos. Otempolivrenainfânciae as práticas lúdicas realizadase preferidas. In:NETO, Carlos. Motricidade ejogo na infância. 2.ed. Rio de Janeiro: Sprint, 1999. cap. 9, p. 142-157.

OLIVEIRA,ZilmadeMoraesRamosde.Jogodepapéis:uma perspectivaparaanálise dodesenvolvimentohumano. 1988. 221f.Tese(DoutoradoemPsicologiaExperimental).UniversidadedeSãoPaulo,SãoPaulo.

PELLEGRINI,Anthony.Applied childstudy: adevelopmental approach. 2.ed.Hillsdale:LawrenceErlbaum, 1991.
PEREIRA,BeatrizOliveira;NETO, Carlos. Otempolivrenainfânciae as práticas lúdicas realizadas e preferidas. Ludens, v. 14,n. 1,p.35-41.jan./mar. 1994.

RAMALHO,MariaHelenadaSilva.Orecreiopré-escolarea motricidade infantilna perspectiva da Teoria da Ecologia do Desenvolvimento Humano. 1996. 196f. Tese(Doutorado emCiênciadoMovimentoHumano).UniversidadeFederalde SantaMaria, SantaMaria.

RODRÍGUEZGÓMEZ,Gregoni;GILFLORES,Javie;GARCÍA JIMÉNEZ, Eduardo. Metodología de la investigación cualitativa. Málaga: Aljibe, 1996.

SERRANO,João;NETO,Carlos. Asrotinasdevidadiáriadascriançascomidadescompreendidasentreos 7eos 10anosnosmeios rural eurbano. In: NETO, Carlos(Ed.).Jogo \& Desenvolvimentoda criança. Lisboa:EdiçõesFMH, 1997.p.206-225.

VYGOTSKI,LevSemiónovic.Obrasescogidas:fundamentosde defectología. Madrid:Visor, 1997.v.5.

\section{Notas}

* MestreemCiênciasdoMovimentoHumanopelaESEF/ URGS

* DoutoraemEducaçãoFísicapelaUFSM.Professorada UCSedaFSG.

***⿰冫⿰亅⿱丿丶丶 LivreDocenteemGinásticaeDoutoremCiências pela UFRGS.DinetordaFEFID/PUCRS.

Recebido:09/09/02

Aceito:05/12/02 
